\title{
REGRESSÃO DOS MÍNIMOS QUADRADOS PARCIAIS PARA ANALISAR A PERCEPÇÃO DOS CUSTOS DE GOVERNANÇA CORPORATIVA EM UMA COOPERATIVA DE CRÉDITO
}

\author{
PARTIAL LEAST SQUARES REGRESSION TO ANALYZE THE PERCEPTION OF \\ CORPORATE GOVERNANCE COST ON A CREDIT COOPERATIVE
}

\begin{abstract}
Resumo
Com o intuito de melhorar a eficiência e transparência das cooperativas de crédito e fortalecer essas cooperativas, o Banco Central do Brasil diagnosticou as características da governança corporativa das cooperativas de crédito e recomendou uma série de boas práticas. Para adoção das práticas de governança corporativa existe um custo associado a essa nova prática. A alocação de recursos em cooperativas é assunto que tem sido pouco discutido nas pesquisas gerenciais. Assim, esse trabalho tem como objetivo estudar a percepção dos custos das práticas de governança corporativa em uma cooperativa de crédito por parte dos associados. Para isso, foi desenvolvido um modelo composto por um índice de percepção dos custos das práticas de governança corporativa. Os resultados encontrados demonstraram que há relacionamento positivo significativo entre as variáveis utilizadas e o índice de percepção dos custos das práticas de governança corporativa. E, além disso, há um relacionamento positivo entre as características intrínsecas dos cooperados e a percepção dos benefícios gerados pela cooperativa.
\end{abstract}

Palavras-chave: governança cooperativa; cooperativa de crédito; mínimos quadrados parciais; percepção; custos.

\begin{abstract}
To improve the efficiency and transparency of credit unions and strengthen these cooperatives, Brazil's Central Bank diagnosed the governance characteristics of credit unions and recommended a number of good practices. To adopt the corporate governance practices there is a cost associated with this new practice. The allocation of resources cooperative is subject that has been little discussed in the management of research. Thus, this work aims to study the perception of the costs of corporate governance practices in a credit union by the member. For this, it developed a model consists of a perception index of the costs of corporate governance practices. Our results indicate that there is significant positive relationship between the variables used and the perception index of the costs of corporate governance practices. And besides, there is a positive relationship between the intrinsic characteristics of the cooperative and the perception of the benefits generated by the cooperative.
\end{abstract}

Keywords: corporate governance; credit unions; partial least squares; perception; costs.

Recebido: 06/07/2015 Aceito: 06/01/2016

Luana Zanetti Trindade1, Sigismundo Bialoskorski Neto²

${ }^{1}$ Faculdade de Economia, Administração e Contabilidade de Ribeirão Preto, Doutoranda em Controladoria e Contabilidade-

luanazanetti@fearp.usp.br- Rua Clemente Ferreira 671- Ribeirão Preto-SP, Jardim São Luis- Cep:14.020.-410

${ }^{2}$ Universidade de São Paulo, Doutorado em Economia Aplicada- sig@usp.br 


\section{Introdução}

S egundo o Instituto Brasileiro de Governança Corporativa- IBGC (2009), a governança corporativa, é o sistema por meio do qual as organizações são dirigidas, monitoradas e incentivadas, envolvendo o relacionamento entre proprietários da organização e a gestão. De acordo com Ventura et al. (2009), a governança corporativa tem como objetivo alinhar os sistemas de controle, monitoramento e incentivos para que as decisões dos gestores sejam realizadas no melhor interesse dos proprietários, assim, ela vem como resposta a registros de expropriação de riquezas por parte dos gestores, que prejudicam os acionistas. Esses registros decorrem do problema de agência dos gestores que baseiam suas atitudes com objetivo de maximizar sua utilidade pessoal e não riqueza dos acionistas, objetivo pelo qual foram contratados.

No contexto de propriedade pulverizada como é o caso das cooperativas, no qual vários agentes contratuais possuem direito residual ao controle, muitos problemas de governança corporativa advêm do fato de os diversos proprietários desejarem exercer o controle de maneira diferente devido a divergências de interesses (BECHT et al., 2005). Portanto, torna-se inviável a tomada de decisões de maneira coletiva, e parte do poder de decisão e controle sobre os ativos da organização é delegado aos gestores, dando origem a um contexto de separação de propriedade e controle. Sem essa separação, os proprietários residuais têm pouca proteção contra ações oportunistas dos agentes de decisão, e isso diminui o valor irrestrito de reivindicações residuais (FAMA; JENSEN, 1983).

Dessa forma, a governança corporativa vem como resposta a essa possível expropriação do capital do principal por parte do agente. A governança tenta minimizar os conflitos de agência, podendo assim, gerar benefícios para a organização.

Entretanto, para adoção dessas práticas de governança corporativa, sendo elas obrigatórias por meio de leis ou normativos ou de forma espontânea, existe um custo associado a essa nova prática. Assim pergunta-se: os custos associados às praticas indicadas de governança corporativas são percebidos pelos membros associados da cooperativa? Isso pode ser importante, pois pode influenciar negativamente a sua adoção uma vez que o cooperado ao ser proprietário da cooperativa tem direito a voto na Assembleia Geral Ordinária.

Assim, esse trabalho tem como objetivo estudar a percepção dos custos das práticas de governança corporativa em uma cooperativa de crédito por parte dos associados ativos. Este trabalho busca contribuir para o entendimento da importância da percepção dos custos das práticas de governança corporativa nas cooperativas de crédito. A motivação deste trabalho é o interesse pela compreensão das estruturas de governança corporativa que geram custos nas cooperativas de crédito brasileiras. Isso porque os custos das práticas de governança corporativa podem impactar na eficiência das organizações, em especial nas cooperativas de pequeno porte. Segundo Millar e Bowen (2011), caso esses custos de governança não sejam considerados, eles podem levar a problemas de eficiência. Com a análise da percepção, é possível identificar se a cooperativa e seus cooperados percebem os custos da governança corporativa, pois são feitos investimentos para cumprimento das práticas, ou seja, os custos de práticas da governança corporativa que podem afetar nas sobras distribuídas.

Para isso, foi desenvolvido um modelo composto por um índice de percepção dos custos das práticas de governança corporativa. Esse índice é formado pela percepção dos cooperados sobre as estruturas de governança corporativa que geram custos para a cooperativa, em relação à transparência da organização, eficiência da gestão, treinamento e capacitação, os próprios custos das práticas de governança corporativa e os benefícios gerados. A seguir, na próxima seção será apresentado o referencial teórico utilizado para elaboração do modelo e também serão explicados os aspectos metodológicos, as variáveis utilizadas e por fim os resultados encontrados.

\section{Referencial Teórico Para Desenvolvimento Do Modelo Estrutural De Percepção Dos Custos Das Práticas De Governança Corporativa}

\subsection{Modelo, variáveis e proxys}

A adoção de mecanismos e estruturas de governança corporativa tem trazido significativos benefícios para as organizações em geral. Nas organizações cooperativas, 
o duplo papel assumido pelos cooperados como proprietário e usuário é um fator muito importante de conhecimento e de gestão. Segreti (2008) destaca que, este duplo papel se reflete em diversos aspectos nas estruturas de governança da organização cooperativa. Ou seja, o cooperado deve ter conhecimento do que é gasto pela organização e os benefícios que lhe são retornados nessa cooperativa, uma vez que ele é o proprietário e usuário.

Nessa linha, Cook (1994) discute as diferenças organizacionais entre investidores e usuários orientados pelas firmas, e relaciona três aspectos que podem trazer implicações à gestão das cooperativas: papel interpessoal; informacional; e decisorial da gestão. Esses aspectos têm efeitos diretos sobre os direitos de propriedades, comportamento gerencial e os incentivos oferecidos, que estão correlacionados ao papel empreendedor do gestor nas decisões, na capacidade de resolução de conflitos e na habilidade de negociação para a alocação de recursos às atividades estratégias das cooperativas.

A principal fonte de conflito nas cooperativas é, basicamente, decorrente do processo de alocação de recursos. No Brasil, a alocação dos direitos de propriedade nas cooperativas é regida pela Lei 5.764/71. Essa lei define em seu art. 24, que o capital da cooperativa deve ser subdividido em quotas-partes, não podendo um único associado subscrever mais de um terço $(1 / 3)$ do total de quotas-partes. Além disso, também são vedados benefícios às quotas-partes ou privilégios a determinados associados.

Assim, nota-se a necessidade de um gestor responsável por gerir as atividades dos cooperados, surgindo ai o conflito de agência, resultado da assimetria de informação entre as partes. Isso ocorre uma vez que o agente que irá administrar os interesses do principal pode ter interesses diferentes ao maximizar suas riquezas que vão contra os interesses dos múltiplos principais da cooperativa. Isso ocorre porque o bem estar dos principais depende das ações do agente.

Destarte, a governança corporativa vem como resposta a essa possível expropriação do capital do principal por parte do agente. A governança tenta minimizar os conflitos de agência, podendo assim, gerar benefícios para a organização.

$\mathrm{O}$ aumento desses benefícios pode ser resultado da governança corporativa, como afirma Ventura et al., (2009). Uma vez que, segundo esses autores, a governança pode proporcionar benefícios para as organizações que a aderem. No caso de cooperativas de crédito esses benefícios seriam as sobras ao final do exercício.

Entretanto, para adoção dessas práticas de governança corporativa, sendo elas obrigatórias por meio de leis ou normativos ou de forma espontânea, existe um custo associado a essa nova prática.

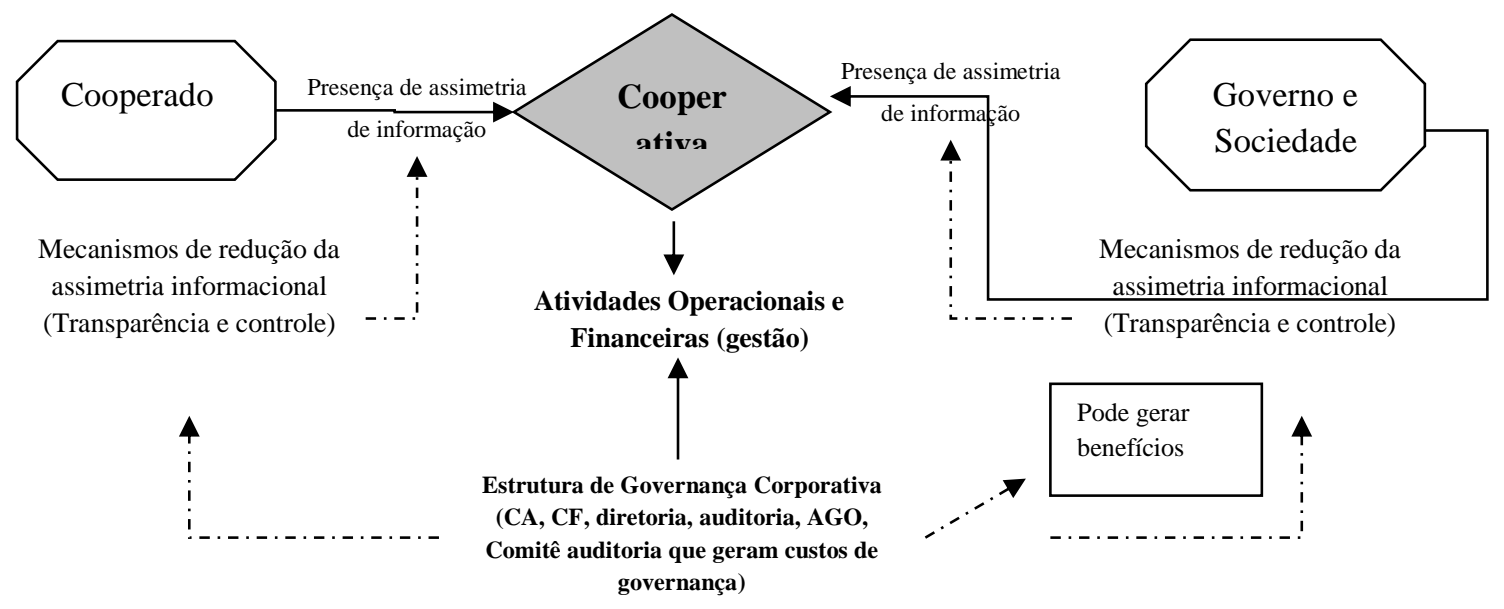

Ilustração 1 - Teoria de Agência dentro das cooperativas

Fonte: Adaptado de REZENDE et al,. (2008). 
As setas contínuas indicam possíveis focos de conflitos de agência resultados da assimetria de informação existente e devido a execução das atividades operacionais e financeiras, que são as áreas sob o controle do agente (gestores). Isso ocorre porque o agente está a serviço do principal (associados, ou stakeholders).

Nas setas tracejadas, têm-se, basicamente, os campos de execução, campo de geração dos conflitos (atividades operacionais e financeiras), bem como os mecanismos que podem ser implementados, pelo principal, como alternativa para a redução da assimetria informacional. Um mecanismo para redução dos conflitos de agência é o uso de estruturas de governança corporativa como: Conselho de Administração, Conselho Fiscal, auditoria, Comitê de Auditoria, AGO e diretoria. Mas para a implantação dessas práticas de governança corporativa a organização incorre em custos de adaptação a governança (custo das práticas de governança corporativa), sendo eles de forma prescritiva e obrigatória ou facultativo. É importante e direito do cooperado ter conhecimento desses novos investimentos que são feitos e quais os possíveis retornos isso pode trazer para ele como associado e para toda a organização.

Como afirma Ventura et al., (2009), a governança corporativa pode gerar benefícios para as organizações que a adotam. Então, é possível como resultado da governança corporativa um benefício para a organização que pode ser repassado para o cooperado, como por exemplo, as sobras que são benefícios pecuniários da atividade. Isso seria resultado de uma gestão mais eficiente e transparente.

Destaca-se que o modelo de governança corporativa proposto, baseado nos pressupostos da teoria de agência, pode representar um fundamento útil as cooperativas. Desse modo, os mecanismos de governança corporativa podem oferecer proteção aos interesses dos associados e auxiliar na minimização dos conflitos e diferenças existentes, além de funcionar como instrumento de correção das falhas existentes no processo de transparência e informação.

Mas Cook (1994) afirma que a alocação de recursos em cooperativas é assunto que tem sido pouco discutido nas pesquisas gerenciais. Ele acrescenta que os conflitos relacionados ao processo de alocação de recursos são resultantes da pobreza do processo utilizado pelos gestores, durante a formulação e a comunicação dos direitos de propriedade. Por isso a importância do cooperado ter conhecimento e percepção dos custos associados às praticas de governança corporativa.

A cooperativa deve informar e ser transparente com o cooperado sobre a alocação dos investimentos feitos na organização em especial os custos de adesão as práticas de governança corporativa que são obrigatórias. E é direito do cooperado ter conhecimento e ter interesse sobre o que é gasto, uma vez que isso poderá impactar seus benefícios futuros.

Assim, com o objetivo de estudar a percepção dos custos das práticas de governança corporativa nas cooperativas de crédito por parte dos associados, foi desenvolvido um modelo composto por um índice de percepção dos custos das práticas de governança corporativa. Esse índice é formado pela percepção dos cooperados sobre as estruturas de governança corporativa que geram custos para a cooperativa, em relação à transparência da organização, eficiência da gestão, treinamento e capacitação, os próprios custos das práticas de governança corporativa e os benefícios gerados. Isso foi utilizado uma vez que essas atividades podem reduzir as assimetrias de informação e os conflitos de agência, gerando possivelmente mais benefícios para a organização e seus associados. Além de se tentar analisar se algumas características intrínsecas impactam nesse índice de governança, como idade, nível de escolaridade e tempo de associação na cooperativa.

São apresentadas as 5 dimensões na tabela 1. Para análise dos níveis de governanças na organização que geram custos de governança corporativa, utilizou como métrica as dimensões que geram um índice de percepção dos custos das práticas de governança corporativa adotada pelas organizações, ou seja, o que compõe a percepção do cooperado sobre os custos de práticas de governança corporativa (KLAPPER e LOVE, 2002; SILVEIRA, 2004; DURDEN e PECH, 2006, SWITZER 2007, LODI 2000, RODRIGUEZ 2005, CLARK, 2005, VENTURA et al., 2009). 
Tabela 1- Modelo de Governança corporativa que geram custos de governança corporativa

\section{Dimensões do índice de percepção dos custos de \\ governança corporativa \\ Características e definições}

Transparência

Gestão e Conselho

Capacitação e treinamento

Benefícios

\section{Características dos} cooperados
Informações financeiras, operacionais e estratégicas fornecidas pela Cooperativa. Grau de confiabilidade nas informações fornecidas pela cooperativa. Os cooperados têm acesso as informações da cooperativa

A Diretoria e os conselhos cumprem suas atribuições de gestão e são eficientes.

A gestão possui qualificação adequada ou recebem treinamento para exercer suas atribuições de forma correta e eficiente aumentando assim o monitoramento e a administração eficiente. Treinamento para os cooperados gerirem melhor seu negócio e conhecerem mais sobre a cooperativa. Treinamento de educação cooperativista para valorização das atividades da organização.

Retorno oferecido pela organização podendo ser pecuniário ou não. Sobras como benefícios pecuniários resultado das atividades da cooperativa de forma eficiente.

Relacionado à idade, nível de escolaridade, frequência de participação na AGO e tempo de associação do respondente do questionário. As referências são avaliadas não pelo seu valor objetivo, mas por um valor subjetivo e pessoal.

Fonte: Elaborado pelos autores

Para identificar a percepção dos custos de governança corporativa nas cooperativas de crédito por parte dos associados foi utilizado um modelo composto de 5 dimensões e 17 variáveis, que foram avaliadas numa escala semântica de 1 a 10.

Para isso se utilizou um modelo de primeira e de segunda ordem. O modelo de índice de percepção dos custos das práticas de governança corporativa é variável latente que foi mensurada a partir de 05 dimensões e 17 questões, que compreendem um conjunto de ações e características que determinam esse índice. $\mathrm{O}$ construto de índice de percepção dos custos das práticas de governança compreende um construto de primeira ordem e as dimensões que o compõe são de segunda ordem.

Foram considerados aspectos referentes a transparência (disclosure) da organização, estrutura de gestão e conselhos, capacitação e treinamentos para melhor administração, e benefícios percebido são os resultados pecuniários ou não pecuniários para $o$ cooperado, e por fim a última dimensão sobre características intrínsecas do cooperado respondente do questionário.

O constructo de transparência é definido como fato de disponibilizar para as partes participantes as informações que sejam de seu interesse (IBGC, 2009), é permitir aos interessados ter uma visão abrangente a respeito do desempenho da corporação (BACEN, 2008). Ou seja, o associado ter acesso as informações da gestão e a cooperativa ser aberta em mostrar suas informações. Já a estrutura de gestão e conselhos tem como função elaborar estratégias, administrar, fiscalizar, analisar e examinar as atividades da organização (BRASIL, 1971)

Quanto ao treinamento e a capacitação são abordados como atividades que a cooperativa oferece para que seus associados aprendam conteúdos informativos sobre suas atividades pessoais podendo ser de ordem financeira, operacional e educação cooperativa. E também para os funcionários para capacitação de suas atividades exercidas na cooperativa e sobre atitudes de educação cooperativa (IBGC, 2009; VENTRUTA et al., 2009).

O benefício percebido é o retorno que o cooperado vai receber da organização, podendo ser pecuniário ou não. As vantagens de participação na cooperativa podem representar a coalizão de interesses em um grupo com caráter social, solidário e voluntário, e a participação econômica necessária para o crescimento empresarial. As melhores tarifas para operações financeiras e apoio técnico por meio de projetos específicos são formas de prestação de serviço. Em relação aos valores monetários distribuídos, eles criam uma situação transparente para o 
membro monitorar o comportamento econômico da organização. (BIALOSKORSKI NETO, 2004; 2005), pois quanto mais conhecimento se tem sobre os possíveis benefícios da governança corporativa mais se espera que os gastos feitos com governança corporativa tragam retorno para a organização e seus associados.

As características intrínsecas são referentes à idade, formação frequência na AGO e tempo como associado, podendo impactar em como cada pessoa tem uma característica subjetiva de perceber as coisas. Como afirmam Tversky e Kahneman (1979), as referências são avaliadas não pelo seu valor objetivo, mas por um valor subjetivo e pessoal. Ela representa uma medida de satisfação, que pode ser associada a cada resultado.

Para mensuração e avaliação do índice de percepção dos custos das práticas de governança adotada pelas cooperativas foi utilizado modelo composto de 5 dimensões e 17 questões que foram avaliadas numa escala semântica, sendo 1 pouco até 10 muito.

Para o entendimento e comparação da pesquisa há a proposição de um modelo para o estudo. O modelo tem como respondentes os associados da cooperativa estudada. Esse modelo é composto pelas seguintes variáveis:

1. A variável "TRANSPARÊNCIA" foi mensurada pela percepção dos cooperados em ter facilidade ao acesso das informações da cooperativa envolvendo área financeira, mostrando a comunicação entre cooperativa e cooperado. A resposta apresentava como escala de 1 até 10 , onde 1 representava pouco e 10 muito.

2. A variável "ESTRUTURA E GESTÃO" foi mensurada pelas questões que tiveram como objetivo identificar a percepção sobre estruturas de governança de gestão existentes na cooperativa em relação a eficiência em suas atribuições.

3. A variável "TREINAMENTO E CAPACITAÇÃO" foi mensurada pelos cursos oferecidos pela cooperativa. As perguntas estavam relacionadas aos treinamentos dos cooperados oferecidos pela cooperativa e sobre educação cooperativista. As respostas apresentavam como escala de 1 até 10 , onde 1 representava pouco e 10 muito.

4. A variável "BENEFÍCIO" foi mensurada pela questão que tratam sobre as sobras geradas aos cooperados. A resposta apresentava como escala de 1 até 10, onde 1 representava pouco até 10 muito.

5. A variável "CARACTERÍSTICAS INTRÍSECAS" foi mensurada por indicadores como idade, nível de escolaridade, tempo de cooperativa e frequência de participação na AGO.

A partir das definições e variáveis que comporiam o modelo estrutural proposto, elaborou-se um conjunto de hipóteses, conforme tabela abaixo.

Tabela 2 - Relações estruturais e hipóteses do modelo estrutural de percepção dos custos das práticas de governança corporativa

\begin{tabular}{|c|c|c|c|}
\hline Hipóteses & Variável & $\begin{array}{l}\text { Coeficiente } \\
\text { Esperado }\end{array}$ & Autores \\
\hline $\mathrm{H}_{1}$ & $\begin{array}{l}\text { Transparência }=>\text { Índice percepção dos custos de } \\
\text { governança corporativa }\end{array}$ & $(+)$ & $\begin{array}{c}\text { Clark (2005); Rodriguez } \\
\text { (2005); Ventura et al., (2009); }\end{array}$ \\
\hline $\mathrm{H}_{2}$ & $\begin{array}{l}\text { Estrutura e gestão }=>\text { Índice percepção dos custos de } \\
\text { governança corporativa }\end{array}$ & $(+)$ & $\begin{array}{l}\text { Clark (2005); Durden e Pech } \\
\text { (2006) }\end{array}$ \\
\hline $\mathrm{H}_{3}$ & $\begin{array}{l}\text { Treinamento e capacitação= }=>\text { Índice percepção dos custos } \\
\text { de governança corporativa }\end{array}$ & $(+)$ & $\begin{array}{c}\text { SEGRETI } \text { et al., } \\
\text { (2005); Ventura } \text { et al., (2009) }\end{array}$ \\
\hline $\mathrm{H}_{4}$ & $\begin{array}{l}\text { Custos diretos de governança }=>\text { Índice percepção dos } \\
\text { custos de governança corporativa }\end{array}$ & $(+)$ & $\begin{array}{l}\text { Clark (2005); Rodriguez } \\
\text { (2005) }\end{array}$ \\
\hline $\mathrm{H}_{5}$ & $\begin{array}{l}\text { Benefícios percebidos }=>\text { Índice percepção dos custos de } \\
\text { governança corporativa }\end{array}$ & $(+)$ & Ventura et al., (2009) \\
\hline $\mathrm{H}_{6}$ & $\begin{array}{l}\text { As características intrínsecas dos cooperados }=>\text { Índice } \\
\text { percepção dos custos de governança corporativa }\end{array}$ & $(+)$ & $\begin{array}{l}\text { Staatz (1987); Fulton (1999). } \\
\text { Tversky e Kahneman (1979) }\end{array}$ \\
\hline
\end{tabular}

Fonte: Elaborado pelos autores

A perspectiva reflexiva utilizada nesse modelo que possibilita a análise das relações entre variáveis, permitindo que essas variáveis sejam observadas utilizando como forma de categorização e mensuração 
fenômenos do mundo real, uma vez que não podem ser observáveis diretamente.

Para isso, o método dos Mínimos Quadrados Parciais (MQP- Partial Least Squares-PLS) é indicado como o mais adequado à estimação dos parâmetros desse modelo proposto (CHIN, 2004)

Segundo Lohmöller (1988), no método PLS as variáveis latentes são estimadas como agregados lineares ou componentes. Não há restrições quanto às características de distribuição dos dados e, devido às suas semelhanças com a análise de componentes principais se evitado os problemas inerentes à estimação de variância negativa.

Outra questão a ser abordada sobre o método PLS está relacionada ao tamanho da amostra, admitindo a utilização de um número pequeno de casos para estimação dos parâmetros, sendo adotada uma das seguintes regras: (a) o número de casos deverá ser dez vezes o número de variáveis observadas do construto constituído pelo maior número de indicadores, caracterizado assim sob uma perspectiva formativa, ou (b) dez vezes a quantidade de caminhos direcionados para um determinado construto do modelo estrutural (CHIN, 2003).

Para avaliar aderências das dimensões e variáveis do modelo estrutural de governança foi utilizado um modelo de primeira e de segunda ordem. O modelo de índice de percepção dos custos das práticas de governança corporativa é uma variável latente que foi mensurada a partir de 05 dimensões e 17 questões, tendo a amostra dentro das regras para a estimação dos parâmetros conforme afirmam Chin (2003) e Lohmöller (1988). As questões compreendem um conjunto de ações e características que determinam o escore de custos das práticas de governança percebido para cada cooperado entrevistado. No entanto, a governança também pode ser mensurada por grupos de variáveis ou dimensões. Essas questões foram norteadas pela literatura de governança corporativa (VENTURA et al., 2009) e percepção (TVERSKY, A.; KAHNEMAN, 1979).

\subsection{Aspectos metodológicos}

Para realização do estudo de percepção dos custos práticas de governança corporativa na cooperativa estudada, foram aplicados questionários aos associados ativos de uma cooperativa de crédito. A técnica questionário "trata-se de um conjunto ordenado e consistente de perguntas a respeito de variáveis e situações que se deseja medir ou descrever" (MARTINS E THEÓPHILO, 2009, p. 93).

O questionário é o principal instrumento de levantamento de dados por amostragem, sendo aplicável a diversas áreas das ciências sociais. $\mathrm{Na}$ presente pesquisa, o questionário se justifica pelo fato de não ser possível obter por fontes secundárias os dados necessários (GUNTHER, 2003).

Segundo Gunter (2003, p.4), "o objetivo da pesquisa determina da forma do instrumento, a maneira da sua aplicação por meio de conceitos e itens, da populaçãoalvo e da amostra". No presente estudo, a aplicação de questionário foi feita por meio impresso, entregue aos associados ativos pessoalmente por funcionários da organização, a fim de aumentar o número de respondentes e tornar a aplicação do instrumento mais eficiente.

As perguntas do questionário foram elaboradas com base nas práticas de governança corporativa indicadas e obrigatórias às cooperativas de crédito segundo o Banco Central e sugeridas pelo IBGC. O questionário é composto de perguntas referentes à percepção dos custos das práticas de governança corporativa. É composto por respostas em escala Likert de 1 a 10 que medem a intensidade de percepção desses custos.

As análises dos resultados do questionário aplicado aos cooperados dessa cooperativa de pequeno porte foram realizadas por meio do método estatístico de equações estruturais (PLS - Partil Least Square), que representa uma técnica analítica que combina uma perspectiva econométrica focando sobre a predição e modelagem de variáveis latentes, resultando numa grande flexibilidade na modelagem teórica. Escolheu-se este modelo, pois se caracteriza como uma técnica mais adequada quando o objetivo da investigação é a previsão ou modelação exploratória, como no caso a percepção.

Tendo-se Rea e Parker (2000) e Bryman (1989) como referência é importante ressaltar que os levantamentos são planejados para medir atitudes, preferências, crenças, comportamentos e opiniões. São realizados a partir de uma amostra de sujeitos e seus dados são coletados, principalmente por meio de questionários, escalas e entrevistas estruturadas.

Essa técnica utilizada é composta de diagramas 
causais que envolvem três componentes principais: indicadores (variáveis observadas medidas), variável latente (constructo, conceito, fator); caminhos relacionados (correlacional, uma trajetória, ou dois sentidos / trajetórias), assim é apropriada quando as variáveis utilizadas para representar um fenômeno não podem ser mensuradas diretamente (Chin, 2004).

Chin (2004) descreve os passos para a análise e uso da técnica de equações estruturais:

1) Criar um modelo teórico, fundamentado em revisão bibliográfica robusta;

2) Construir um diagrama de trilhas (caminho) das relações causais (ou influenciadoras);

3) Transformar o diagrama num conjunto de modelos estruturais usando o software;

4) Escolher a matriz de entrada de dados apropriada para estimar o modelo proposto.

O software smart PLS gera um conjunto de parâmetros de validade e confiabilidade, automaticamente, e um relatório de análise com os seguintes índices de adequação do modelo:

$\checkmark$ R2 - coeficiente de determinação indica a quantidade de variância comum entre a variável dependente e a independente. Ou seja, esse índice mede a força ou explica a relação entre a variável dependente e a independente, quanto maior o R2, maior é o poder explicativo do modelo (COOPER, et al., 2004; COZBY, 2003);

$\checkmark$ Confiabilidade Composta $\quad$ - representa confiabilidade e a consistência interna da variável latente com seus indicadores. Como regra para decisão de corte, Hair Jr., et al., (1998) sugere um índice de 0,50;

Alfa de Cronbach - avalia a consistência interna de um constructo, examinando a correlação média das variáveis entre si, Cozby (2003) recomenda um ponto de corte de 0,7 ;

$\checkmark$ Variância Média Extraída - representa outra medida de confiabilidade (validade convergente), reflete o montante total da variância nos indicadores considerados no constructo (variável latente). Quanto maior a variância extraída, mais representativos são os indicadores do constructo, Hair Jr., et al., (1998) sugere um índice de 0,50.

O processo de avaliação do modelo estrutural, para identificar se há equações suficientes para resolver os coeficientes estimados:

- Interpretar os resultados e, se necessário, modificar o modelo de forma a melhorar os indicadores obtidos anteriormente e estimar, à luz da teoria revista, os melhores relacionamentos possíveis entre as variáveis latentes.

- Replicar estatisticamente as variáveis do modelo estrutural por meio da técnica bootstrapping, que compara os resultados com o parâmetro da distribuição t de Student (nível de 0,05 e 120 amostras de uma mesma população), recomenda-se eliminar os índices das variáveis latentes menores que 1,96.

Por fim, os questionários foram aplicados aos cooperados ativos de uma pequena cooperativa de crédito, mas previamente a aplicação, foram aplicados $5 \%$ dos questionários como pré-testes para identificar limitações e possíveis dificuldades dos respondentes. Após esse préteste, como não foram identificados problemas, foram aplicados os questionários definitivos. Esses $5 \%$ de questionários pré-testes ( 5 respondentes) foram usados na amostra para desenvolvimento dos testes estatísticos, completando 81 respondentes.

\section{Análise E Discussão Dos Resultados}

A partir dos dados coletados com cooperados 81 de uma cooperativa de pequeno porte que frequentam a cooperativa, em modelo estrutural que contém 5 dimensões e em 17 itens avaliados (indicadores). Devido ao número pequeno de respondentes da amostra usou-se como critério de significância com nível até $20 \%$ para que houvesse um maior número de variáveis no modelo utilizado. Dessa forma, as variáveis aqui utilizadas foram significantes até o valor de $20 \%$ de nível de significância, com uma confiabilidade de $80 \%$.

Destarte, buscou neste modelo identificar um índice de percepção dos custos das práticas de governança corporativa nas cooperativas de crédito por parte dos associados ativos. 


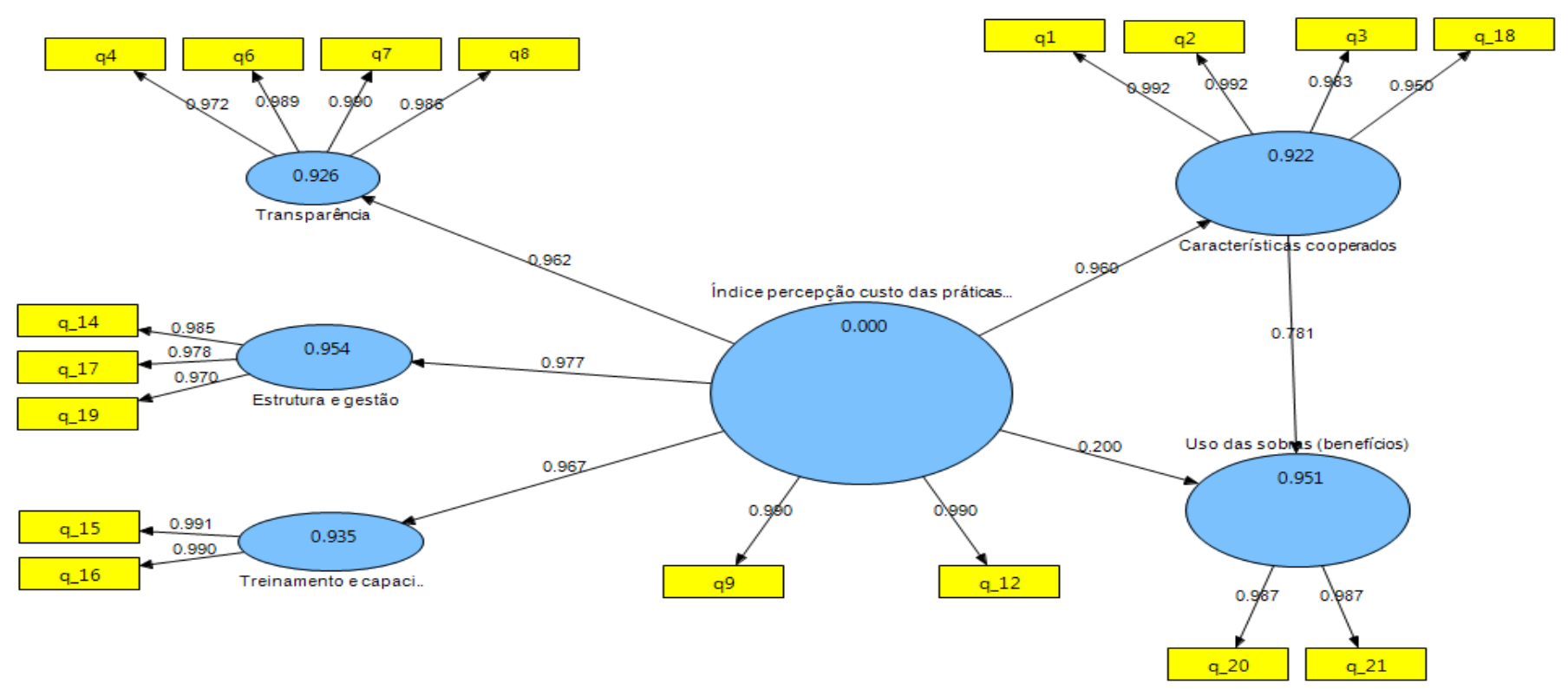

Figura 1 - Modelo de índice de percepção dos custos das práticas de governança corporativa Fonte: Elaborado pelos autores com base nos dados coletados.

$\mathrm{Na}$ análise do modelo estrutural, pode-se verificar que a dimensão transparência apresenta um $\mathrm{R}^{2}$ de 0,926 e um efeito positivo no índice de percepção dos custos das práticas de governança corporativa; Estrutura e gestão apresenta um efeito positivo com um $\mathrm{R}^{2}$ 0,954; Treinamento e capacitação apresenta uma efeito positivo no índice de percepção do custo das práticas de governança corporativa e um $\mathrm{R}^{2} 0,935$; Uso das sobras e benefícios apresentam um $\mathrm{R}^{2}$ 0,951 e um efeito positivo no índice de custos das práticas de governança corporativa; e as características intrínsecas apresenta um efeito positivo e um $\mathrm{R}^{2}$ 0,922 no índice de percepção do custo das práticas de governança corporativa e um efeito positivo nos benefícios.

Portanto, o índice de percepção dos custos de práticas de governança corporativa percebido pelos cooperados, avaliado em cinco dimensões, apresentou um $\mathrm{R}^{2} \mathrm{e}$ coeficientes significativos para 5 dimensões.

Isso pode significar que o índice de percepção dos custos das práticas de governança corporativa são relacionados com a transparência, estrutura e gestão das cooperativas, treinamento e capacitação e pelas características intrínsecas dos cooperados.
Além disso, o uso dos benefícios, ou seja, o uso das sobras que retornariam para os cooperados influenciam de forma positiva a percepção e a formação desse índice por parte dos cooperados. Ou seja, quanto mais se percebe o uso desses benefícios também se percebe um aumento do índice de custos das práticas de governança corporativa, havendo uma relação positiva entre benefícios e o índice de custos das práticas de governança corporativa.

Ademais, as características dos cooperados influenciam a formação do índice de percepção dos custos das práticas de governança corporativa. Destarte há uma relação entre esse índice e o tempo de associação na cooperativa, idade do cooperado e nível de escolaridade juntamente com a frequência de participação na AGO.

Dessa forma, é possível validar as hipóteses utilizadas nessa análise, podendo afirmar que de fato há uma percepção dos custos das práticas de governança corporativa por parte dos cooperados.

$\mathrm{Na}$ Tabela 3 a seguir, são apresentados os indicadores de confiabilidade gerados pelo smart PLS e os pontos de corte sugeridos pela literatura. 
Tabela 3 - Resultados estatísticos do modelo processado pelo PLS

\begin{tabular}{lcccc}
\hline & AVE & $\begin{array}{c}\text { Composite } \\
\text { Reliability }\end{array}$ & R square & $\begin{array}{c}\text { Cronbachs } \\
\text { Alpha }\end{array}$ \\
\hline Características cooperados & 0.959302 & 0.989502 & 0.921714 & 0.985756 \\
Estrutura e gestão & 0.955627 & 0.984758 & 0.954250 & 0.976769 \\
Transparência & 0.968081 & 0.991824 & 0.925958 & 0.988992 \\
Treinamento e capacitação & 0.981004 & 0.990411 & 0.935483 & 0.980637 \\
$\begin{array}{l}\text { Uso das sobras (benefícios) } \\
\text { Índice percepção custo das práticas de }\end{array}$ & 0.973598 & 0.986622 & 0.950774 & 0.972883 \\
governança corporativa & 0.979978 & 0.989888 & & 0.979570 \\
Padrão de corte & $\mathbf{2 0 , 5 \geq}$ & $\mathbf{2 0 , 6 \geq}$ & $\mathbf{2 0 , 2} \geq$ & $\geq \mathbf{0 , 7} \geq$ \\
\hline
\end{tabular}

Fonte: Dados da pesquisa

Conforme dados da Tabela 3, se obteve o valor mínimo do AVE 0,5 e de confiabilidade composta para algumas dimensões do modelo, de acordo com o sugerido pela literatura (HAIR Jr et al., 1998). Destarte observa-se que todos os construtos estão com variância média extraída (Average Variance Extracted - AVE) acima de $50 \%$. Esses resultados vão ao encontro dos resultados esperados segundo a literatura utilizada.

Tabela 4 - Coeficiente da regressão e a estatística T

\begin{tabular}{|c|c|c|c|c|c|}
\hline \multicolumn{6}{|c|}{ Total Effects (Mean, STDEV, T-Values) } \\
\hline & & Sample & Standard & Standard & \\
\hline & Original & Mean & Deviation & Error & T Statistics \\
\hline $\begin{array}{l}\text { Características cooperados -> Uso } \\
\text { das sobras (benefícios) }\end{array}$ & 0.781493 & 0.626142 & 0.222142 & 0.222142 & 3.517980 \\
\hline $\begin{array}{l}\text { Índice percepção } \\
\text { práticas custo das } \\
\text { corporativa }\end{array}$ & 0.960059 & 0.721871 & 0.329936 & 0.329936 & 2.909837 \\
\hline $\begin{array}{lcl}\text { Índice } & \text { percepção } & \text { custo das } \\
\text { práticas } & \text { de } & \text { governança } \\
\text { corporativa->Estrutura e gestão }\end{array}$ & 0.976857 & 0.879906 & 0.137304 & 0.137304 & 7.114575 \\
\hline $\begin{array}{l}\text { Índice percepção custo das } \\
\text { práticas de gov. corp. } \\
\text { Transparência }\end{array}$ & 0.962267 & 0.838072 & 0.177892 & 0.177892 & 5.409276 \\
\hline $\begin{array}{l}\text { Índice percepção custo das } \\
\text { práticas de gov. corp. } \\
\text { Treinamento e capacitação }\end{array}$ & 0.967204 & 0.801219 & 0.229629 & 0.262805 & 4.212024 \\
\hline $\begin{array}{l}\text { Índice percepção custo das } \\
\text { práticas de gov. corp. -> Uso das } \\
\text { sobras (benefícios) }\end{array}$ & 0.950243 & 0.714617 & 0.326943 & 0.326943 & 2.906451 \\
\hline
\end{tabular}

Fonte: Dados da pesquisa 
Essa tabela 4 indica o coeficiente da regressão e a estatística $\mathrm{T}$, que tem como objetivo identificar se os valores T-teste (valores próximos das setas que unem as variáveis ou construtos) que devem ser superiores a 1,96 para que os coeficientes sejam considerados diferentes de zero. De acordo com os dados encontrados, todos estão superiores a 1,96 .

Os resultados demonstraram que há relacionamento positivo significativo entre as variáveis utilizadas e o índice de percepção dos custos das práticas de governança corporativa. E, além disso, há um relacionamento positivo entre as características intrínsecas dos cooperados e a percepção dos benefícios (sobras) gerados pela cooperativa.

Assim, pelos dados encontrados, as variáveis de características dos cooperados, treinamento e capacitação e o uso das sobras estão relacionados à formação do índice de percepção dos custos das práticas de governança corporativa. Assim como transparência e a estrutura e a gestão apresentam valores significativos que compões esse índice e também estão relacionadas.

\section{Considerações Do Modelo Estrutural De Percepção Dos Custos Das Práticas De Governança Corporativa Em Cooperativas De Crédito}

Esta pesquisa explorou a aplicação da modelagem de equações estruturais com o método PLS (Partial Least Square) para analisar a percepção dos cooperados ativos sobre os custos de governança corporativa em uma cooperativa de crédito. Em relação aos resultados e conclusões obtidas, com esta pesquisa, constatou-se, a partir do modelo estrutural proposto que a transparência influencia positivamente o índice de percepção dos custos das práticas de governança corporativa percebido pelos cooperados, pois os coeficientes foram estatisticamente significantes. Ou seja, o nível de transparência apresentado pela cooperativa está relacionado a percepção dos custos de governança. Assim, quanto mais transparente a organização, maiores poderão ser a percepção dos custos de governança corporativa, pois os cooperados tem mais acesso as informações.

Além disso, a estrutura e gestão influenciam positivamente o índice de percepção dos custos das práticas de governança corporativa percebido pelos cooperados. Assim, quanto mais estruturada e organizada a gestão, maiores poderão ser as percepções dos cooperados sobre os custos de governança corporativa, ou seja, os cooperados percebem os investimentos feitos na gestão para que esta se formalize e organize.

As características dos cooperados influenciam positivamente o índice de percepção dos custos das práticas de governança corporativa percebido pelos cooperados. Isso indica que a heterogeneidade dos cooperados exerce influência sobre a percepção. O perfil do cooperado, como idade, tempo de associação e nível de escolaridade determinam uma maior ou menor percepção dos custos de governança corporativa. Além disso, a percepção do uso dos benefícios também é influenciada positivamente pelas características dos cooperados.

Nesse mesmo sentido, o uso dos benefícios (sobras) influencia positivamente o índice de percepção dos custos das práticas de governança corporativa percebido pelos cooperados. Ou seja, os cooperados que recebem mais benefícios percebem mais os custos de governança corporativa e isso também pode ser influenciado porque percebem os benefícios que a governança corporativa gera a organização.

Assim, as 6 hipóteses da pesquisa foram aceitas, conforme apresentadas na tabela a seguir. 
Tabela 5 - Resultados das hipóteses do modelo estrutural de percepção dos custos das práticas de governança corporativa

\begin{tabular}{|c|c|c|c|c|}
\hline Hipóteses & Variável & $\begin{array}{c}\text { Coefic. } \\
\text { Esperado }\end{array}$ & $\begin{array}{c}\text { Coefic. } \\
\text { Encontrado }\end{array}$ & Autores \\
\hline $\mathrm{H}_{1}$ & $\begin{array}{l}\text { Transparência = > Índice percepção dos custos } \\
\text { de governança corporativa }\end{array}$ & $(+)$ & $(+)$ & $\begin{array}{l}\text { Clark (2005); } \\
\text { Rodriguez (2005); } \\
\text { Ventura et al., } \\
\text { (2009); }\end{array}$ \\
\hline $\mathrm{H}_{2}$ & $\begin{array}{l}\text { Estrutura e gestão }=>\text { Índice percepção dos } \\
\text { custos de governança corporativa }\end{array}$ & $(+)$ & $(+)$ & $\begin{array}{l}\text { Clark (2005); } \\
\text { Durden e Pech } \\
\quad(2006)\end{array}$ \\
\hline $\mathrm{H}_{3}$ & $\begin{array}{l}\text { Treinamento e capacitação= }>\text { Índice percepção } \\
\text { dos custos de governança corporativa }\end{array}$ & $(+)$ & $(+)$ & $\begin{array}{l}\text { SEGRETI et al., } \\
\text { (2005); Ventura } \text { et } \\
\text { al., (2009) }\end{array}$ \\
\hline $\mathrm{H}_{4}$ & $\begin{array}{l}\text { Custos diretos de governança }=>\text { Índice } \\
\text { percepção dos custos de governança corporativa }\end{array}$ & $(+)$ & $(+)$ & $\begin{array}{c}\text { Clark (2005); } \\
\text { Rodriguez (2005) }\end{array}$ \\
\hline $\mathrm{H}_{5}$ & $\begin{array}{l}\text { Benefícios percebidos }=>\text { Índice percepção dos } \\
\text { custos de governança corporativa }\end{array}$ & $(+)$ & $(+)$ & $\begin{array}{c}\text { Ventura et al., } \\
\text { (2009) }\end{array}$ \\
\hline $\mathrm{H}_{6}$ & $\begin{array}{l}\text { As características intrínsecas dos cooperados = } \\
>\text { Índice percepção dos custos de governança } \\
\text { corporativa }\end{array}$ & $(+)$ & $(+)$ & $\begin{array}{l}\text { Staatz (1987); } \\
\text { Fulton (1999). } \\
\text { Tversky e } \\
\text { Kahneman (1979) }\end{array}$ \\
\hline
\end{tabular}

Fonte: Dados da pesquisa

Dentre as limitações da pesquisa destaca-se o número de cooperados entrevistados (via questionário) (81), pois, existem, aproximadamente, 12000 cooperados, na cooperativa pesquisada. Apesar das restrições quanto à generalização dos resultados, eles foram coerentes com o referencial teórico, havendo a confirmação das hipóteses testadas. Uma limitação dessa pesquisa são os valores elevados de correlação entre as variáveis, mas isso pode ser resultado de uma amostra pequena. Assim, como ação frente a multicoliariedade existente (altos valores de correlação encontrados), é possível segundo Corrar et al., (2009) utilizar os resultados encontrados para compreender a relação entre as variáveis utilizadas na pesquisa e não tentar interpretar os coeficientes de regressão encontrados. A presença de multicolineariedade no modelo de mensuração, pelo fato de existir correlação entre as variáveis é comum, e pode não ser considerado um problema (ALENCAR; 2009).

Destarte, como sugestão para pesquisas futuras poderia ser feita uma análise considerado um intervalo maior de cooperados ou cooperativas. Além disso, poderia ser feio uma pesquisa comparando a percepção entre cooperados e gestores e entre cooperados de cooperativas de seguimentos diferentes e portes diferentes. Também poderia ser aplicado esse questionário de percepção as cooperativas com naturezas diferentes, pois os 3 modelos de cooperativas existentes citados por Feng Li (2010) poderiam apresentar resultados diferentes devido as culturas organizacionais e estratégias diferentes que influenciam a percepção do cooperado, podendo ser um indicador de quais as estruturas de governança adequadas para cada modelo de cooperativa.

Esta pesquisa pode contribuir para o investimento das organizações cooperativas em ações de práticas de governança corporativa que geram benefícios tanto para os cooperados como para a organização, como afirma a literatura sobre o tema. E, além disso, essa pesquisa preenche a lacuna sobre a percepção dos cooperados sobre custos de governança, que até então apresentam poucas pesquisas. A percepção dos cooperados sobre os custos de governança corporativa representam o conhecimento das atividades da cooperativa por parte dos cooperados, mostrando que eles possuem conhecimento substancial sobre a organização que podem contribuir para a redução dos conflitos de agência, principalmente em cooperativas de crédito, onde as normas de governança corporativa 
apresentam maior impacto devido as obrigatoriedades do Banco Central.

Por fim, os dados encontrados no estudo de caso dessa pequena cooperativa de crédito não podem ser generalizados, porque se aplicam apenas a essa organização. Para a generalização dos dados, seriam necessários novos estudos.

\section{Referências}

BECHT, M; BOLTON, P; ROELL, A. Corporate Governance and Control. ECGI

Working Paper Series. Working Paper No. 02/2002. Updated August 2005.

BRASIL. Lei n. 5.764 de 16 de dezembro de 1971. Define a Política Nacional de Cooperativismo, institui o regime jurídico das sociedades cooperativas, e dá outras providências. Diário Oficial da União, Brasília (DF), 16 dez. 1971.

BRYMAN, A. Research methods and organization studies. London: Routledge, 1989.

CHIN, W. W.; MARCOLIN, B. L.; NEWSTED, P. R. A partial least squares latent variable modeling approach for measuring interaction effects: results from a Monte Carlo simulation study and an electronic mail emotion/ adoption study. Information Systems Research, Hanove,v. 14, n. 2, p. 189-217, 2003.

CHIN, W. W. PLS-Graph. Version 3.00. build 1060. Houston: University of Houston, 2004.

CLARK, R. C. Corporate governance changes in the wake of the Sarbanes-Oxley Act: a morality tale for policymakers too. Harvard Law and Economics Discussion Paper, Cambridge, n. 525, p. 1-46, $2005 . \quad$ Disponível em: <http://papers.ssrn.com/sol3/papers.cfm?abstract_i $\mathrm{d}=808244>$. Acesso em: 28 maio 2012.

COOK, M.L. (1994). The Role of Management Behavior in Agricultural Cooperatives. Journal of Agricultural Cooperation, 42-66.
COOPER, DONALD R. e SCHINDLER, PAMELA S. 2004. Métodos de Pesquisa em Administração. 7a. Porto Alegre : Bookman, 2004.

COZBY, Paul C. 2003. Métodos de pesquisa em ciências do comportamento. [trad.] Paula Inez Cunha GOMIDE, Emma OTTA e José de Oliveira SIQUEIRA. São Paulo: Atlas, 2003.

DURDEN, C.; PECH, R. The increasing cost of corporate governance: decision speed-bumps for managers. Corporate Governance, Oxford, v. 6, n. 1, p. 84-95, 2006.

FAMA, E. F, JENSEN, M. C. Separation of Ownership and Control. Journal of Law and Economics. v.. 26, nº. 2, p. 301-325, 1983.

FENG, LI. On the nature of cooperatives: a system of attributes perspective. In: FENG, LI Motivation, Coordination and Cognition in Cooperatives. Thesis Erasmus University. 2010. 136p.

FULTON, M. Cooperatives and member commitment. The Finnish Journal of Business Economics, Helsinki, v. 4, p. 418-437, 1999. Special issue: Role of cooperative entrepreneurship in modern market environment, LTA 1999

HAIR Jr., J. et al. Análise multivariada de dados. 6 ed. Porto Alegre: Bookman, 2009.

INSTITUTO BRASLEIRO DE GOVERNANÇA CORPORATIVA (IBGC). Código das melhores práticas de governança corporativa. 4. ed. São Paulo, 2009. Disponível em: <http://www.ibgc.org.br/CodigoMelhoresPraticas. aspx>. Acessoem: 7 set. 2011.

KLAPPER, L.; LOVE, I. Corporate governance, investor protection, and performance in emerging markets. World Bank Policy research, working paper N. 2818, 2002. 
LODI, J. B. Governança corporativa: o governo da empresa e o conselho de administração. 3. ed. Rio de Janeiro: Campus, 2000.

LOHMÖLLER, J.The PLS program system: Latent variables paths analyses with partial least squear estimation.Multivariate Behavior Research, v.23, p.125-127,1988.

REA, L. M.; PARKER, R.A. Metodologia de pesquisa: do planejamento à execução. São Paulo: Pioneira, 2000.

\section{REZENDE, A. J.; SALGADO, A. L.; DALMÁCIO,} F. Z., Uma análise do nível de disclosure das atividades operacionais, econômicas e financeiras dos clubes brasileiros. $15^{\circ}$ Congresso Brasileiro de Custos. Anais... Curitiba, 2008.

RODRIGUEZ, G. M. Governança corporativa: identificação dos principais fatores que inibem a adesão das companhias abertas ao Novo Mercado da Bovespa sob o enfoque de custos. 2005. $193 \mathrm{f}$. Dissertação (Mestrado em Controladoria e Contabilidade Estratégica) - Centro Universitário Álvares Penteado, São Paulo, 2005.

SILVEIRA, A. D. M. Governança corporativa e estrutura de propriedade: determinantes e relação com o desempenho das empresas no Brasil. 2004. 245 f. Tese (Doutorado) - Faculdade de Economia Administração e Contabilidade, Universidade de São Paulo, São Paulo, 2004.

SEGRETI, J. B.; PELEIAS, I. R.; RODRIGUES, G. M. Custos da Atividade de Governança Corporativa sob o enfoque da Controladoria Moderna. In: CONGRESSO INTERNACIONAL DE CUSTOS, 11., 2005, Florianópolis. Anais...Florianópolis, 2005. p. 15.

STAATZ, J. M. Farmer cooperative theory: recent developments. Research Report, N. 84. Washington: Agricultural Cooperative Services, 1987.
SWITZER.L. N. Corporate governance, SarbanesOxley, and small-cap firm performance. The Quarterly Review of Economics and Finance, Champaign-Urbana, v. 47, p. 651-666, 2007.

TVERSKY, A.; KAHNEMAN, D. Prospect theory: an analysis of decision under risk. Econometrica, Ohio, v. 47, n. 2, p. 263-229, 1979.

VENTURA, E. C. F. (Coord.). Governança cooperativa: diretrizes e mecanismos para fortalecimento da governança em cooperativas de crédito. Brasília, DF: Banco Central do Brasil, 2009. 